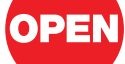

SUBJECT AREAS:

CLIMATE-CHANGE

ECOLOGY

CLIMATE SCIENCES

COMMUNITY ECOLOGY

TROPICAL ECOLOGY

Received

17 January 2013

Accepted

16 April 2013

Published

3 May 2013

Correspondence and requests for materials should be addressed to S.U. (S.Uthicke@aims. gov.au)

\section{High risk of extinction of benthic foraminifera in this century due to ocean acidification}

\author{
S. Uthicke' ${ }^{1}$ P. Momigliano ${ }^{1,2}$ \& K. E. Fabricius ${ }^{1}$
}

\begin{abstract}
'Australian Institute of Marine Science, PMB No 3, Townsville, Queensland 4810, Australia, 2 Department of Biological Sciences, Macquarie University, Sydney, 2109 NSW, Australia.
\end{abstract}

Increased atmospheric $\mathrm{CO}_{2}$ concentrations lead to decreased $\mathrm{pH}$ and carbonate availability in the ocean (Ocean Acidification, OA). Carbon dioxide seeps serve as 'windows into the future' to study the ability of marine invertebrates to acclimatise to OA. We studied benthic foraminifera in sediments from shallow volcanic $\mathrm{CO}_{2}$ seeps in Papua New Guinea. Conditions follow a gradient from present day $\mathrm{pH} / \mathrm{pCO}$ to those expected past 2100 . We show that foraminiferal densities and diversity declined steeply with increasing $p \mathrm{CO}_{2}$. Foraminifera were almost absent at sites with $\mathrm{pH}<7.9\left(>700 \mu \mathrm{atm} p \mathrm{CO}_{2}\right)$. Symbiont-bearing species did not exhibit reduced vulnerability to extinction at $<7.9 \mathrm{pH}$. Non-calcifying taxa declined less steeply along $\mathrm{pCO}_{2}$ gradients, but were also absent in samples at $\mathrm{pH}<7.9$. Data suggest the possibility of an $\mathrm{OA}$ induced ecological extinction of shallow tropical benthic foraminifera by 2100 ; similar to extinctions observed in the geological past.

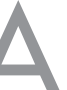

tmospheric carbon dioxide $\left(\mathrm{CO}_{2}\right)$ concentrations are nearly $40 \%$ above pre-industrial levels, and are likely to double by the end of this century ${ }^{1}$. The absorption of atmospheric carbon dioxide by the oceans decreases $\mathrm{pH}$ and carbonate availability ${ }^{2}$ ('ocean acidification', $\mathrm{OA}$ ). These changes can have deleterious effects on marine invertebrates relying on calcification ${ }^{3,4}$. Volcanic carbon dioxide seeps $\mathrm{s}^{5,6} \mathrm{can}$ provide proxies to investigate how calcifying marine organisms acclimatise to exposure to OA. Recent studies of $\mathrm{CO}_{2}$ seeps in shallow temperate and tropical marine ecosystems provided the first data on ecosystem-wide changes caused by OA. These studies documented negative effects of OA on calcifying organisms including corals, echinoderms, gastropods, crustose coralline algae and foraminifera ${ }^{5-8}$. In contrast, seagrasses, microalgae or non-calcifying macroalgae either benefitted from increased DIC availability or were resilient to $\mathrm{pH} / \mathrm{DIC}$ changes $^{5-10}$. At the tropical seeps, coral diversity and structural complexity sharply dropped as $p \mathrm{CO}_{2}$ values approached those expected for the end of this century, while coral cover remained unaffected ${ }^{5}$.

Benthic foraminifera are a diverse group of large protists (up to $2 \mathrm{~cm}$ ) that have an organic wall, form carbonate tests though biotic calcification or form tests through agglutination of sediment particles. Tropical foraminifera have high calcification rates and are important contributors to carbonate sediments. The tests of calcifying foraminifera are made of either high- or low magnesium calcite (Mg-calcite), while only a few taxa produce aragonite $^{11}$. High $\mathrm{Mg}$-calcite is the most soluble form of carbonate, and organisms producing high-Mg-calcite are considered particularly vulnerable to OA.

Many tropical foraminiferal taxa live in symbiosis with unicellular dinoflagellates, diatoms, green or red algae or retaining chloroplasts from algal food and are thus mixotrophic, while the remainder are predominantly heterotrophic. Several studies have investigated the effects of OA on benthic foraminifera. Experiments using $\mathrm{CO}_{2}$ to manipulate seawater chemistry on four species of diatom-bearing and two dinoflagellate-bearing species found only weak effects of reduced $\mathrm{pH} /$ increased $\mathrm{pCO}_{2}{ }^{12,13}$, while other studies found stronger effects ${ }^{14,15}$. A previous field study around a Mediterranean $\mathrm{CO}_{2}$ seep showed that assemblages shifted from calcifying to agglutinate assemblages, and diversity declined at $\mathrm{pH} \sim 7.8^{7}$. Also, a foraminiferal species living on seagrasses was absent near tropical $\mathrm{CO}_{2}$ seeps at $\mathrm{pH}<7.9$ where its calcification was reduced ${ }^{4}$.

Here, we investigate changes in the diverse assemblages of tropical sediment-associated foraminifera along natural $\mathrm{CO}_{2}$ gradients at $\mathrm{CO}_{2}$ seeps in Milne Bay Province, Papua New Guinea (PNG). Assemblages can be considered acclimatized to high $\mathrm{CO}_{2}$ through long-term exposure ( $>70$ years of volcanic seep activity) to $p \mathrm{CO}_{2}$ concentrations as predicted for later this century $\left(490\right.$ to $\left.>1370 \mu \mathrm{atm} \mathrm{pCO}_{2}{ }^{16}\right)$. Previous studies have suggested that $\mathrm{CO}_{2}$ uptake by photosynthesis elevates $\mathrm{pH}$ in the diffusive boundary layer and may thus provide partial 
protection against OA to mixotrophic groups ${ }^{17,18}$. The seeps investigated here are located within the 'Coral Triangle', an area of six Central Pacific nations that harbour the most diverse marine ecosystems on earth. The high diversity of the PNG assemblages, consisting of both mixotrophic and heterotrophic taxa (Supplementary Table 1), provided a unique opportunity to investigate the relative vulnerabilities to OA across taxonomic and trophic groupings.

\section{Results}

Seawater chemistry contrasted strongly between the 12 control and seep sites, with mean values generally ranging from 8.08 to $7.52 \mathrm{pH}$ units and 369 to $11603 \mu \mathrm{atm} p \mathrm{CO}_{2}$, respectively (Supplementary Table 2). One extreme site assumed $\mathrm{pH}$ values of $\sim 7.0$ and $p \mathrm{CO}_{2}$ values of $>5000 \mu \mathrm{atm} p \mathrm{CO}_{2}$. With the exception of that site, calcite and aragonite saturation values at each location remained well above 1.0 (the value at which carbonate theoretically dissolves). Mean total alkalinity was $2326 \mu \mathrm{mol} \mathrm{\textrm {kg } ^ { - 1 }}(\mathrm{N}=134, \mathrm{SD}=66)$. Thus $95 \%$ of all alkalinity values were between 2197 and $2456 \mu \mathrm{mol} \mathrm{kg}{ }^{-1}$, a range we used together with the $\mathrm{pH}$ measurements from all stations to calculate $\mathrm{pCO}_{2}$ concentrations (Fig. $1 \mathrm{~A}$ ). These $\mathrm{pH}$ measurements showed a good correlation to the long term averages for the 12 core sites (Supplementary Table 2, $\mathrm{R}^{2}=0.89, \mathrm{p}<0.0001$ ).

Concentrations of inorganic carbon (IC) in the sediments declined significantly with declining $\mathrm{pH}$ (linear model, Fig. $1 \mathrm{~B}$, Table 1), from nearly $100 \%$ carbonate sediment $(\mathrm{IC}=12 \%)$ at ambient $\mathrm{pH}$ to nearly zero in most samples below $\mathrm{pH}$ 7.7. Sediment organic carbon and nitrogen were unrelated to $\mathrm{pH}\left(\mathrm{C}: \mathrm{R}^{2}=0.01, \mathrm{p}=0.58 ; \mathrm{N}: \mathrm{R}^{2}<0.01\right.$, $\mathrm{p}=0.99)$. Data found were on a low level typical for coral reef sediments (organic-C: average: $0.28 \%, \mathrm{SD}=0.21 \% ; \mathrm{N}$ : average $=$ $0.03 \%, \mathrm{SD}=0.02 \%)$. Because of the low level of organic content, the fact that values do not differ between seeps and control areas and that most foraminifera investigated are epibenthic or epiphytic it is unlikely that dissolution driven by interstitial respiratory processes contributed to the observed patterns.

Water collected over the benthos showed no significant (ANOVA, $\mathrm{p}=0.1509)$ difference in the concentration of arsenic between control $\left(\right.$ mean $\left.=1.62 \mu \mathrm{g} \mathrm{L}^{-1}, \mathrm{SD}=0.08 \mu \mathrm{g} \mathrm{L}^{-1}\right)$ and high (mean $=$ $\left.1.88 \mu \mathrm{g} \mathrm{L}^{-1}, \mathrm{SD}=0.50 \mu \mathrm{g} \mathrm{L}^{-1}\right) \mathrm{CO}_{2}$ sites, and values were in the range on typical marine samples $\left(1-2 \mu \mathrm{g} \mathrm{L}^{-1}\right)$. Sediments had slightly higher arsenic concentrations directly at the main seeps (which emit almost pure $\mathrm{CO}_{2}{ }^{5}$;) compared with the control sites (Seeps: mean $=12.8 \mathrm{mg} \mathrm{kg}{ }^{-1}, \mathrm{SD}=9.8 \mathrm{mg} \mathrm{kg}^{-1}, \mathrm{~N}=4$; Controls: $7.1 \mathrm{mg} \mathrm{kg}^{-1}, \mathrm{SD}=1.8 \mathrm{mg} \mathrm{kg}^{-1}, \mathrm{~N}=5$ ), most likely reflecting the low carbonate content in the seep sediments. Concentrations in sediments were low compared to those at other volcanic vents (e.g., Ambitle Island, PNG: range: $52-33,200 \mathrm{mg} \mathrm{kg}^{-119}$ ). In addition, diverse and abundant foraminiferal communities have been described under sediment and water column arsenic concentrations
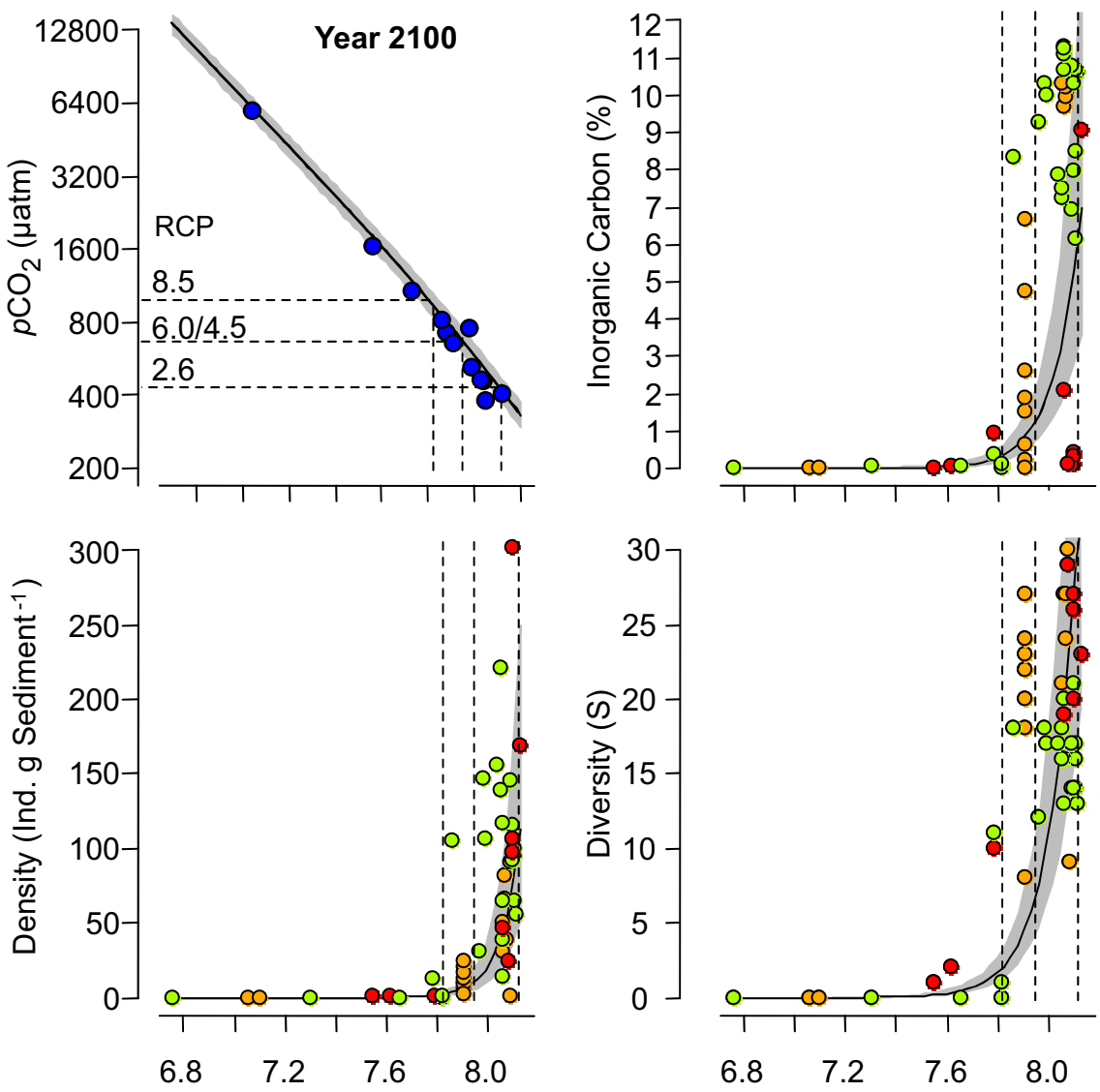

$\mathrm{pH}_{\text {Total }}$

Figure $1 \mid$ Changes in sediments and foraminiferal assemblages along $p \mathrm{CO}_{2}$ gradients at the three $\mathrm{CO}_{2}$ seep and three control sites. Relationships between $\mathrm{pH}_{\text {Total }}$ and $p \mathrm{CO}_{2}$ in the seawater (A), the total inorganic carbon of the sediment (B), total foraminiferal density (C), and total diversity (D). The black lines represents linear model fits, grey areas mark ranges (A): assuming highest and lowest measured temperatures and alkalinity), or $95 \%$ confidence intervals (B-D). Dashed lines demark predicted $\mathrm{CO}_{2}$ concentrations and corresponding pH values at the end of this century following representative concentration pathways ${ }^{21}\left(\mathrm{RCP} 2.6: p \mathrm{CO}_{2}=421 \mu \mathrm{atm}\right.$; SCP 6.0 to 4.5: $p \mathrm{CO}_{2}=670 \mu \mathrm{atm} ; \mathrm{RCP} 8.5: p C \mathrm{CO}_{2}=936 \mu$ atm $)$. Blue symbols in (A) represent $\mathrm{pH}$ and $\mathrm{pCO}_{2}$ concentrations at the main stations presented in Supplementary table 2. Other colours represent the sample locations (Upa-Upasina: green, Esa'Ala: orange, Dobu: red). 
$>10$ times those reported here ${ }^{20}$. Arsenic and ten further metal contaminants measured in water above the benthos showed no differences between seep and non-seep sites, and were in ranges expected in pristine seawater (Supplementary Table 3). Temperature loggers recorded only $0.3^{\circ} \mathrm{C}$ warmer conditions on the benthic surfaces at the seeps compared to the control sites, and annual temperature extremes also only varied by this amount (Seeps: average: $29.6^{\circ} \mathrm{C}$, maximum and minimum: $32.2^{\circ} \mathrm{C}$ and $26.8^{\circ} \mathrm{C}$; Controls: $29.3^{\circ} \mathrm{C}$, maximum and minimum: $31.8^{\circ} \mathrm{C}$ and $26.7^{\circ} \mathrm{C}$ ), again in contrast to some other seep sites (e.g., Ambitle surface sediments: seep temperatures: $45-98^{\circ} \mathrm{C}$, vs. control site: $30.2^{\circ} \mathrm{C}^{19}$ ).

Foraminifera were abundant at control sites (mean densities: 93 individuals $\mathrm{g}^{-1}$ sediment, $\mathrm{SD}=54$ individuals $\mathrm{g}^{-1}$ sediment). Densities declined steeply with increasing $p \mathrm{CO}_{2}$ (Table 1, Fig. $1 \mathrm{C}$ ), and foraminifera were almost absent at $p \mathrm{CO}_{2}$ conditions predicted for the end of this century under all but the most optimistic emission scenarios (RCP2.6, peak at $440 \mu \mathrm{atm} p \mathrm{CO}_{2},{ }^{21}$; Fig. $1 \mathrm{~A}, \mathrm{C}$ ). The density of mixotrophic and heterotrophic taxa decreased at the same rate, and their slopes of decline did not differ significantly (Table 1). In other words, both groups followed the same trajectory towards extinction with increasing $p \mathrm{CO}_{2}$. The slope of decline was less steep for agglutinate compared to calcifying taxa; however, this group was overall rare $(1.0 \%$ of the assemblage at ambient $\mathrm{pH}, \mathrm{SD}=1.4 \%)$, and they were also absent in any samples at $\mathrm{pH}<7.9$.

A total of 49 foraminiferal taxa were detected in the 50 sediment samples (Supplementary Table 1). Total foraminiferal diversity also declined with increasing $p \mathrm{CO}_{2}$ (Table 1 , Fig. $1 \mathrm{D}$ ).

The comparisons of the slopes for diversity directly mirrored those of densities: there was no significant difference in the rate of diversity loss between mixotrophic and heterotrophic taxa (Table 1). The loss of diversity was significantly slower for agglutinate taxa, but only three taxa were recorded.

Additional dive searches ( $>5 \mathrm{~h}$ total) at Upa-Upasina for living large mixotrophic foraminifera on algal, seagrass and coral rubble substrata revealed that several species can be readily found at the control site (Amphistegina spp., Calcarina spp., Heterostegina depressa, Marginopora vertebralis), whereas none could be detected at locations with reduced $(<\sim 7.9) \mathrm{pH}$ values.

Table 1 Results of linear models describing the response of sediment inorganic carbon, foraminiferal density and diversity to decreased $\mathrm{pH}$. Density and diversity data are further split into a) mixotrophic vs. heterotrophic taxa, and b) calcifying vs. agglutinate taxa. A statistical comparison of the slopes for these comparisons is also given. Models were fitted after natural log transformation of the dependent variable

\begin{tabular}{lrrrr} 
Source & Slope (SE) & $\dagger$ & $P$ & $R^{2}$ \\
\hline Inorganic Carbon & $9.60(0.94)$ & 10.22 & $<0.0001$ & 0.68 \\
Densities & & & & \\
Total & $13.20(1.11)$ & 11.86 & $<0.0001$ & 0.74 \\
Mixotrophic & $13.44(1.18)$ & 11.44 & $<0.0001$ & 0.73 \\
Heterotrophic & $11.14(1.17)$ & 9.52 & $<0.0001$ & 0.65 \\
$\quad$ Mixo- vs. Heterotrophic & & -1.387 & 0.169 & \\
Calcifying & $13.13(1.11)$ & 11.86 & $<0.0001$ & 0.74 \\
Agglutinate & $5.50(1.99)$ & 2.77 & 0.0081 & 0.12 \\
$\quad$ Calcifying vs. Agglutinate & & -3.35 & 0.0012 & \\
Diversity & & & & \\
Total & $9.25(0.86)$ & 10.75 & $<0.0001$ & 0.70 \\
Mixotrophic & $11.22(1.10)$ & 10.63 & $<0.0001$ & 0.70 \\
Heterotrophic & $10.33(1.17)$ & 8.83 & $<0.0001$ & 0.61 \\
$\quad$ Mixo- vs. Heterotrophic & & -0.83 & 0.4100 & \\
Calcifying & $11.26(1.07)$ & 10.49 & $<0.0001$ & 0.69 \\
Agglutinate & $5.79(2.16)$ & 2.68 & 0.0100 & 0.11 \\
$\quad$ Calcifying vs. Agglutinate & & -2.27 & 0.0256 & \\
\hline
\end{tabular}

A permutational multivariate analysis of variance (Permanova) indicated significant differences in foraminiferal assemblage composition between the three sampling locations (Supplementary Table 4). The main difference between locations was that mixotrophic species were dominant at one of the locations (UpaUpasina) and heterotrophic species dominated at the other two locations (Supplementary Table 5). A distance-based redundancy analysis (dbRDA) showed that the relative contribution of most taxa to the foraminiferal assemblage did not change along the $\mathrm{CO}_{2}$ gradient (Supplementary Fig. 1). $p \mathrm{CO}_{2}$ explained only a small (5.2\%) albeit significant proportion of the variation in relative abundances between samples (Pseudo- $\mathrm{F}=2.41, \mathrm{p}=0.0133$ ). This confirmed that most taxa disappeared at a similar rate with increasing $p \mathrm{CO}_{2}$. Exceptions were three species (two Elphidium spp. and Amphistegina lessonii) which increased slightly in relative importance at intermediate $\mathrm{pCO}_{2}$ (Supplementary Fig. 1).

Closer inspection of the three samples that had intermediate foraminiferal densities at $<7.9-8.0 \mathrm{pH}$ (Fig. 1) showed that most of their foraminifera were Amphistegina spp. and Elphidium spp., i.e., taxa that appeared to increase in relative importance with elevated $p \mathrm{CO}_{2}$. However, many of these specimens had a corroded or pitted appearance (Fig. 2). This appearance was not detected in any of the control samples in Milne Bay at present-day $p \mathrm{CO}_{2}$ conditions, or in sediment core slices $>1000 \mathrm{yr}$ of age from the Great Barrier Reef $\left({ }^{22}\right.$, Fig. 2). The pitted appearance is similar to that observed in another Amphistegina species under experimental $\mathrm{CO}_{2}$ increase ${ }^{23}$.

\section{Discussion}

Foraminiferal density and diversity at the control sites in PNG were high and similar to those observed on the Great Barrier Reef ${ }^{22,24}$ or other sites in $\mathrm{PNG}^{25}$. Our data show no sign of acclimation by benthic foraminifera to high $p \mathrm{CO}_{2}$, although a proportion of genotypes will have lived near the seeps for many generations (their reproduction is partly non-dispersive asexual, as well as through gametes). Our analyses along the $\mathrm{pH} / \mathrm{pCO}_{2}$ gradients around the seeps in PNG suggested that all common tropical foraminiferal species will likely be ecologically extinct at the $\mathrm{CO}_{2}$ conditions predicted for the year 2100 , except under the most optimistic scenario. However, that scenario is unlikely, requiring immediate drastic emission cuts and negative net emission (i.e. carbon sequestration) in the second half of this century ${ }^{26}$.

Several mass extinctions of deep sea benthic foraminifera occurred in the geological past, most of which were linked to increased $p \mathrm{CO}_{2}$ and/or temperature ${ }^{27,28}$, but some geological studies from shallow reef environments also observed increased foraminiferal dominance when corals became rare ${ }^{29}$. None of these previous extinctions were as severe as the ecological or even taxonomic extinction in shallow carbonate areas we predict. Previous natural $p \mathrm{CO}_{2}$ increases occurred one to two orders of magnitude slower and were associated with less reduced calcite or aragonite saturation states than the anthropogenic increases presently observed ${ }^{28}$.

Contrary to our initial hypothesis, no shift towards mixotrophic taxa was observed. We assumed that photosymbiont-bearing taxa might be less vulnerable to OA because carbon fixation may increase $\mathrm{pH}$ in their diffusive boundary layer ${ }^{18}$; this can lead to $\mathrm{pH}$ differences of $>0.8$ units between day and night ${ }^{17,18}$. A recent study in foraminifera, however, showed that these increases cannot compensate for decreased $\mathrm{pH}$ in ambient water ${ }^{30}$. We hypothesized that agglutinate taxa which do not rely on calcification might replace calcifying species. In our study, density and diversity of agglutinate taxa declined less steeply than calcifying taxa. However, agglutinate taxa were too rare to fill the niches vacated by calcifying taxa.

Carbonate sediments at seeps disappeared at calcite or aragonite saturation states $>1.0$ (Supplementary Table 2). Previous experiments have shown test dissolution and corrosion in temperate heterotrophic foraminifera at $>900 \mu \mathrm{atm} p \mathrm{CO}_{2}{ }^{31}$; although one species 

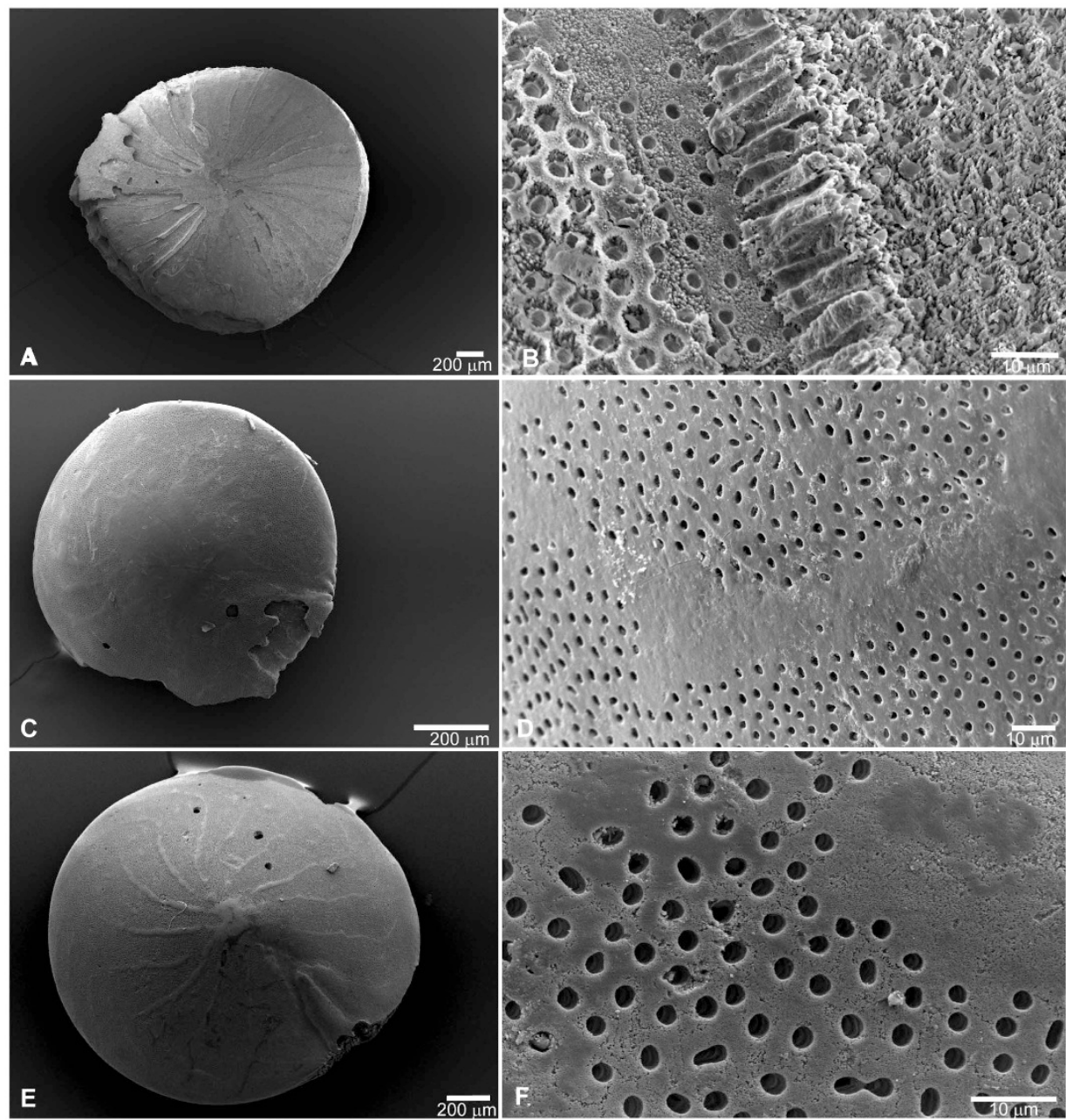

Figure 2 Scanning Electron Micrographs of Amphistegina spp. (A-B) illustrate specimens with corroded and pitted appearance, as found in many foraminifera from sample locations with $\mathrm{pH}$ 7.9-8.0. The example shown is from "Esa'Ala elevated $p \mathrm{CO}_{2}$ " (see Table 1), where average $p \mathrm{CO}_{2}$ over 15 samples was $444 \mu \mathrm{atm}$. (C-D) represent a sample from the control location near the Esa'Ala seep (average $p \mathrm{CO}_{2}: 369 \mu$ atm, Table 1). (E-F) show a sample from a sediment core slice of the Great Barrier Reef (Edward 7, 130-140 cm depth), carbon dated as 1361 years before present (68.5\% probability interval: $1157-1564^{22}$,). This sample illustrates that the test corrosion observed near $\mathrm{CO}_{2}$ vents is not part of the 'normal' taphonomic process.

still calcified at $1900 \mathrm{pCO}_{2}{ }^{32}$. However, our electron microscopy and sediment inorganic carbon data showed corrosion of foraminifera at 7.9-8.0 $\mathrm{pH}$, and absence of biogenic carbonate accumulation, suggesting that carbonate dissolution began at $\mathrm{pCO}_{2}$ levels of $\sim 450 \mu \mathrm{atm}$. Dissolution of foraminifera and sediment was previously observed under elevated $\mathrm{pCO}_{2}$ and can start at aragonite saturations states above $3^{33,34}$. Indeed, most biogenic carbonates dissolved at much higher saturation values than predicted from abiotic carbonates $^{35}$. Thus, in addition to the described direct ecological impacts, the loss of benthic foraminifera, together with dissolution and loss of biogenesis of carbonate by other organisms under nearfuture $p \mathrm{CO}_{2}$ conditions may also have far-reaching ecological flowon effects.

\section{Methods}

50 sediment samples were collected during two expeditions to the seep sites ${ }^{5}$ in August 2010 and April 2011. Samples were collected at various distances from the three seeps (Esa'Ala, Upa-Upasina, Dobu Island) and their control sites. Samples of the top $1 \mathrm{~cm}$ sediment were sourced from 4 to $15 \mathrm{~m}$ depth. At each site, three haphazard samples were taken, and pooled into one sample.

For the estimation of foraminiferal abundances, sediments were rinsed over a $63 \mu \mathrm{m}$ sieve. After drying $\left(>24 \mathrm{~h}, 60^{\circ} \mathrm{C}\right)$, all foraminifera were collected from subsamples until 200 specimens per sample were obtained. This yield could not be achieved for some of the samples collected near the seep sites. In that case, all available sediment was searched. We collected only intact specimens which showed no sign of degradation and little damage ('optimally preserved', sensu ${ }^{36}$ ) under the dissection microscope at $25 \times$ magnification. These specimens are regarded as a good representation of the present-day (time averaged over the last few years) biocoenosis ${ }^{36}$ Taxa were determined under a dissection microscope, following Uthicke et al. $2010^{24}$ The dry weights of both sediment and foraminifera were determined to calculate foraminiferal densities. A subsample of foraminifera was observed via Scanning Electron Microscopy (SEM) in order to identify signs of corrosion. Organic matter was removed by incubating the tests in $2 \% \mathrm{NaClO}$ for $1 \mathrm{~h}$ at $60^{\circ} \mathrm{C}$. Foraminiferal tests were then dehydrated in 100\% ethanol, mounted on SEM stubs and sputter-coated with gold and visualized on a JEOL JSM-5410LV scanning electron microscope.

A subsample of the sediment prior to rinsing and sieving was dried and ground for total carbon and nitrogen determination. Samples were analyzed on a Truspec $\mathrm{C} / \mathrm{N}$ Analyser (Leco). After acidification (2 M hydrochloric acid), organic carbon in the sediments was measured using a TOC-V Analyser (Shimadzu, equipped with a SSM5000A Solid Sample Module).

Arsenic concentrations in sediments were determined on acid digested $\left(\mathrm{HNO}_{3} /\right.$ $\mathrm{HClO}_{4}$ ) subsamples, by Hydride Generation Atomic Absorption Spectrometry using a Thermo SOLAAR M Atomic absorption spectrometer. To assess surface sediment temperatures, six temperature loggers (TidbiT v2, Hobo Data loggers) were deployed on the substrata of all seep and control sites for 363 days (April 2011 to April 2012; one logger from Upa-Upasina failed and data are reported for 5 loggers only).

Seawater carbonate chemistry data were based on those presented in ${ }^{5}$, complemented by additional samples from April 2011 following the same procedures and based on total alkalinity and dissolved inorganic carbon (DIC) measurements. Arsenic and 10 common heavy metal pollutants were analysed from triplicate (unless marked otherwise in Supplementary Table 3) samples from each of the seep and control sites on an ICP-MS using an octapole reaction system to limit matrix interferences. Samples for these analyses were collected in two opposite seasons, in May and December 2012. 
Linear models were used to test for relationships between average $\mathrm{pH}$ and the dependent sediment chemistry variables, and foraminiferal total density and diversity, and density and diversity of individual groups. Models were fitted after log transformation (natural logarithm) of the dependent variable. The initial models included depth and $\mathrm{pH}$, but depth was removed from the final models because it did not explain a significant amount of variation for any of the parameters (Supplementary Table 6). Slopes of two groups were compared by adding 'groups', ' $\mathrm{pH}$ ' and their interaction term into the model and accepting slopes as homogenous when the interaction term was non-significant.

Distance-based redundancy analysis (dbRDA) was used to investigate patterns in assemblage composition across samples. Initial permutation tests showed that depth had no effect of assemblage patterns (Pseudo-F $=1.62, \mathrm{p}=0.0958$ ), but location (Esa'Ala, Upa-Upasina and Dobu Island) affected distributions (Pseudo-F $=6.57$ $\mathrm{p}<0.0001$ ). These location effects were removed (partialled out) because they were not of interest in the context of our study. The mean $\mathrm{pH}$ value for each sample was converted to $p \mathrm{CO}_{2}$ and used as environmental variable. DbRDA was conducted on a Bray-Curtis distance matrix of fourth-root transformed relative abundance data.

Single-factor permutational multivariate analysis of variance (PERMANOVA) was used to investigate the significance of differences in assemblage composition between sample locations. PERMANOVA post-hoc tests presented here were based on 10,000 permutations, using type III sums of squares and permutation of residuals under a reduced model. Subsequent to PERMANOVA, similarity percentage (SIMPER) was used to investigate which taxa contributed most to between-group differences. DbRDA and linear model analyses were performed in R. PERMANOVA and SIMPER analyses were conducted in Primer 6.0.

1. Feely, R. A., Doney, S. C. \& Cooley, S. R. Ocean acidification: Present conditions and future changes in a high- $\mathrm{CO}_{2}$ world. Oceanography 22, 39-47 (2009).

2. Feely, R. A. et al. Impact of anthropogenic $\mathrm{CO}_{2}$ on the $\mathrm{CaCO}_{3}$ system in the oceans. Science 305, 362-366 (2004).

3. Ries, J. B. Skeletal mineralogy in a high- $\mathrm{CO}_{2}$ world. J. Exp. Mar. Biol. Ecol. 403, 54-64 (2011).

4. Uthicke, S. \& Fabricius, K. Productivity gains do not compensate for reduced calcification under near-future ocean acidification in the photosynthetic benthic foraminifera Marginopora vertebralis. Global Change Biology 18, 2781-2791 (2012).

5. Fabricius, K. E. et al. Losers and winners in coral reefs acclimatized to elevated carbon dioxide concentrations. Nature Climate Change 1, 165-169 (2011).

6. Hall-Spencer, J. M. et al. Volcanic carbon dioxide vents show ecosystem effects of ocean acidification. Nature 454, 96-99 (2008).

7. Dias, B. B., Hart, M. B., Smart, C. W. \& Hall-Spencer, J. M. Modern seawater acidification: the response of foraminifera to high- $\mathrm{CO}_{2}$ conditions in the Mediterranean Sea. Journal of Geological Society 167, 843 (2010).

8. Martin, S. et al. Effects of naturally acidified seawater on seagrass calcareous epibionts. Biology Letters 4, 689 (2008).

9. Porzio, L., Buia, M. C. \& Hall-Spencer, J. M. Effects of ocean acidification on macroalgal communities. J. Exp. Mar. Biol. Ecol. 400, 278-287 (2011).

10. Johnson, V. R. et al. Responses of marine benthic microalgae to elevated $\mathrm{CO}_{2}$. Marine Biology online first, 1-12, doi:DOI 10.1007/s00227-011-1840-2 (2011).

11. Blackmon, P. D. \& Todd, R. Mineralogy of some foraminifera as related to their classification and ecology. Journal of Paleontology, 1-15 (1959).

12. Fujita, K., Hikami, M., Suzuki, A., Kuroyanagi, A. \& Kawahata, H. Effects of ocean acidification on calcification of symbiont-bearing reef foraminifera. Biogeosciences Discuss. 8, 1809-1829 (2011).

13. Vogel, N. \& Uthicke, S. Calcification and photobiology in symbiont-bearing benthic foraminifera and responses to a high $\mathrm{CO}_{2}$ environment. J. Exp. Mar. Biol. Ecol. 424, 15-24 (2012).

14. Kuroyanagi, A., Kawahata, H., Suzuki, A., Fujita, K. \& Irie, T. Impacts of ocean acidification on large benthic foraminifers: Results from laboratory experiments. Marine Micropaleontology 7, 190-195 (2009).

15. Reymond, C. E., Lloyd, A., Kline, D. I., Dove, S. G. \& Pandolfi, J. M. Decline in growth of foraminifer Marginopora rossi under eutrophication and ocean acidification scenarios. Global Change Biology 19, 291-302, doi:10.1111/ gcb.12035 (2013)

16. Moss, R. H. et al. The next generation of scenarios for climate change research and assessment. Nature 463, 747-756 (2010).

17. De Beer, D. \& Larkum, A. Photosynthesis and calcification in the calcifying algae Halimeda discoidea studied with microsensors. Plant, Cell \& Environment 24, 1209-1217 (2001).

18. Koehler-Rink, S. \& Kuehl, M. Microsensor studies of photosynthesis and respiration in larger symbiotic foraminifera. I. The physico-chemical microenvironment of Marginopora vertebralis, Amphistegina lobifera and Amphisorus hemprichii. Mar. Biol. 137, 473-486 (2000)
19. Price, R. E. \& Pichler, T. Distribution, speciation and bioavailability of arsenic in a shallow-water submarine hydrothermal system, Tutum Bay, Ambitle Island, PNG. Chemical geology 224, 122-135 (2005)

20. McCloskey, B. Foraminiferal responses to arsenic in a shallow-water hydrothermal system in Papua New Guinea and in the laboratory. PhD thesis, University of Miami (2009).

21. Meinshausen, M. et al. The RCP greenhouse gas concentrations and their extensions from 1765 to 2300. Climatic Change 109, 213-241 (2011).

22. Uthicke, S., Patel, F. \& Ditchburn, R. Elevated land runoff after European settlement perturbs persistent foraminiferal assemblages on the Great Barrier Reef. Ecology 93, 111-121 (2012)

23. McIntyre-Wressnig, A., Bernhard, J. M., McCorkle, D. C. \& Hallock, P. Non-lethal effects of ocean acidification on the symbiont-bearing benthic foraminifer Amphistegina gibbosa. MEPS 472, 45-60 (2013).

24. Uthicke, S., Thompson, A. \& Schaffelke, B. Effectiveness of benthic foraminiferal and coral assemblages as water quality indicators on inshore reefs of the Great Barrier Reef, Australia. Coral Reefs 29, 209-225 (2010).

25. Langer, M. R. \& Lipps, J. H. Foraminiferal distribution and diversity, Madang reef and lagoon, Papua New Guinea. Coral Reefs 22, 143-154 (2003).

26. Arora, V. K. et al. Carbon emission limits required to satisfy future representative concentration pathways of greenhouse gases. Geophys. Res. Lett 38, L05805 (2011).

27. Zachos, J. C. et al. Rapid acidification of the ocean during the Paleocene-Eocene thermal maximum. Science 308, 1611-1615 (2005).

28. Hönisch, B. et al. The Geological Record of Ocean Acidification. Science 335 1058-1063 (2012).

29. Scheibner, C. \& Speijer, R. P. Late Paleocene-early Eocene Tethyan carbonate platform evolution: A response to long- and short-term paleoclimatic change. Earth-Science Reviews 90, 71-102 (2008).

30. Glas, M. S., Fabricius, K. E., de Beer, D. \& Uthicke, S. The $\mathrm{O}_{2}, \mathrm{pH}$ and $\mathrm{Ca}^{2+}$ microenvironment of benthic foraminifera in a high $\mathrm{CO}_{2}$ World. PLoS ONE 7 , e50010 (2012).

31. Haynert, K., Schönfeld, J., Riebesell, U. \& Polovodova, I. Biometry and dissolution features of the benthic foraminifer Ammonia aomoriensis at high $\mathrm{pCO}_{2}$. Mar Ecol Prog Ser 432, 53-67 (2011).

32. Dissard, D., Nehrke, G., Reichart, G. J. \& Bijma, J. Impact of seawater $\mathrm{pCO}_{2}$ on calcification and $\mathrm{Mg} / \mathrm{Ca}$ and $\mathrm{Sr} / \mathrm{Ca}$ ratios in benthic foraminifera calcite: results from culturing experiments with Ammonia tepida. Biogeosciences 81, 81-93 (2011).

33. Yamamoto, S. et al. Threshold of carbonate saturation state determined by $\mathrm{CO}_{2}$ control experiment. Biogeosciences 9, 1441-1450 (2012).

34. Yates, K. \& Halley, R. $\mathrm{CO}_{3}{ }^{2-}$ concentration and $\mathrm{pCO}_{2}$ thresholds for calcification and dissolution on the Molokai reef flat, Hawaii. Biogeosciences Discussions 3 123-154 (2006)

35. Morse, J. W., Andersson, A. J. \& Mackenzie, F. T. Initial responses of carbonaterich shelf sediments to rising atmospheric $\mathrm{pCO}_{2}$ and. Geochimica et Cosmochimica Acta 70, 5814-5830 (2006).

36. Yordanova, E. K. \& Hohenegger, J. Taphonomy of larger Foraminifera: relationships between living individuals and empty tests on flat reef slopes (Sesoko Island, Japan). Facies 46, 169-204 (2002).

\section{Acknowledgements}

We thank the Councillors of the Dobu RLLG and the Traditional Owners of the seep sites for allowing us to survey their reefs. We are grateful for comments by R. Albright on an earlier draft. The research was funded by the Australian Institute of Marine Science.

\section{Authors contributions}

S.U. conducted and designed experiments, analysed data and wrote the MS. P.M. Analysed data and foraminiferal samples, and contributed to the writing. K.F. conceived the overall seep project and contributed to writing and analysis.

\section{Additional information}

Supplementary information accompanies this paper at http://www.nature.com/ scientificreports

Competing financial interests: The authors declare no competing financial interests.

License: This work is licensed under a Creative Commons

Attribution-NonCommercial-NoDerivs 3.0 Unported License. To view a copy of this license, visit http://creativecommons.org/licenses/by-nc-nd/3.0/

How to cite this article: Uthicke, S., Momigliano, P. \& Fabricius, K.E. High risk of extinction of benthic foraminifera in this century due to ocean acidification. Sci. Rep. 3, 1769; DOI:10.1038/srep01769 (2013) 